\title{
MICROBIAL CONTROL OF WHITE GRUBS IN NEPAL: THE WAY FORWARD
}

\author{
Yubak Dhoj GC (PhD) ${ }^{1}$
}

\begin{abstract}
Nepalese economy is largely dependent on agriculture. Over the time, there has been gradual transformation in the agricultural production system and the hitherto dominant chemical based agricultural system has been gradually changing with the latest aspects of bio-rational approaches. Emphasis towards these aspects has been seen both in the governmental and non-governmental level through their commitments in long term prospective plans. However, there is long way to go towards bio-rational approach of pest control in Nepal. This aspect is newer concept in case of Nepal

Institute of Agriculture and Animal Science (IAAS), Department of Entomology, Rampur, in support of Helvetas had initiated bio-pesticides production. The major effort was the production and use of biopesticide based on fungal pathogen (Metarhizium anisopliae Sorokin) against white grubs in particular and soil insect in general. The research was carried out for about a decade and results so far indicated the ample scope of producing and using this agent against this dreaded pest. The research results so far obtained are at get set position, however, to gear up the further works, it has been felt that joint efforts from possible counterparts such as Nepal Agricultural Research Council (NARC), IAAS, Department of Agriculture (DOA), private organisations, NGOs and INGOs would be vital. It has been realised to form national working groups for the development of microbial pest control. Major lead should be taken by national organisations in full support of private organisations. This paper has been brought forth in order to bring into the information of the works so far done in Nepal and to arouse the interest among the possible counterparts, producers, consumers, planners, and policy makers.
\end{abstract}

Key words: Bio-rational compounds, Bio-pesticides, IPM, Metarhizium anisopliae, white grubs

\section{BACKGROUND}

With increasing population pressure, the need for the adoption of improved technologies has been widely realised at all levels (planners to rural farmers). Use of new technologies has increased crop intensities, and has lead to the adoption of high yielding varieties and high chemical input (fertilisers and pesticides). These practices have lead not only to increased production and productivity and greater monetary returns to the farmers but also invited severe problems such as insect pests to an extent never faced in the past. Losses due to insect pests is regarded one of the important production constraints of the major crop produce. Several dozens of pest involve in crop damages. Some of them have gained nationally important pests notably, Helicoverpa, white grubs (many species of Coleopteran beetles within the Scarabaeidae family), aphids (Aphis sp), white fly (Bemisia tabaci), caterpillar pests (mainly moth larvae) depending on the season and locality. Field reports from various sources indicate that white grubs are among the most difficult soil pest insects to control in cash crops (e.g. vegetable, potato or ginger) and food crops (e.g. maize, millet, etc.) grown in upland areas. Collaborating institutes of the Sustainable Soil Management Programme (SSMP/ Helvetas-Nepal), IAAS, Rampur and several other organisations have reported white grubs as a major limiting factor affecting soil productivity. They were, for

\footnotetext{
${ }^{1}$ Ministry of Agriculture and CooperativeS, Nepal, yubakgc@yahoo.com
} 
example, causing an average of about $25 \%$ yield loss in groundnut (Arachis hypogea) in Baitadi (far western Nepal) district, 30\% losses of finger millet in Parbat (western Nepal) district (personal communication with farmers and field observation) and up to $50 \%$ losses in maize and millet in Sindhupalchowk district. Similarly, they are reported to be an increasing nuisance in several other crops such as cereals, vegetables and cash crops from eastern to western parts of Nepal as reported by Government organisations and several INGOs/ NGOs. Despite of the increasing pest problem, their systematic control initiative involving quantification of losses, identification of most damaging species, pest biology and ecofriendly control measures has not yet been implemented countrywide. However, research results conducted by IAAS, Rampur in different parts of the country has indicated ample opportunity for controlling white grubs using fungus based (Metarhizium anisopliae) microbial control agent. In addition to the research results of Nepal, the scopes of the work have been greatly supported by the research results conducted in European conditions mainly Switzerland and other central European countries. Moreover, this is not harmful to the human beings and useful organism rather it is environmentally benign approach which should replace or reduce the input of chemical pesticides in Nepalese agriculture.

\section{CURRENT MEASURES OF WHITE GRUBS CONTROL}

Because of the lack of eco-friendly control measures such as biological control, insecticides are only the readily available and dominant means of white grub control in Nepal. This situation is mainly due to poorly developed infrastructure coupled with lack of trained manpower and pesticide oriented pest control methods prevailing in the country. In addition, alternative pest control measures that are compatible with existing farmers practices are not readily available in the country which has also accelerated into the reliance on pesticides. These situations have compelled to the farmers for using highly persistent and ecologically destructive pesticides. In recent years, pesticide use in Nepal has increased several folds, and this trend is likely to continue and even accelerate in the near future. The area along the open and porous border with India where agrochemical production is growing without much quality control is particularly vulnerable. In some instances banned insecticide such as BHC (class II, moderately hazardous, banned in 28 countries) followed by metacid (class 1a, extremely hazardous, banned in five countries) are still been used in some areas (Dahal, 1995).

The most commonly used insecticides in Nepal include BHC- dust, Aldrine and Endosulphane and several other poor graded chemical pesticides. Highly hazardous chemical like Phorate (Thimet) is still been used against soil insects without considering their residual effect inside the soil and likely hazardous effects to the non target organisms. In a farmer's field survey in Parbat district, farmers also use some fungicides aiming to control white grubs because of the confusion between fungicides and insecticides. Moreover, they treat such chemicals indiscriminately and very inappropriately which has a very damaging effect on the water bodies as well as to the beneficial micro-organisms inside the soil environment. Farmers have popular misconception that pesticides are though out as "medicines" to kill pests but not as "poison" that also affects other living organisms. Because of this, farmers first attempt to use highly poisonous compounds rather than seeking moderate group of chemicals in the beginning. Their search on other biorational compounds is very far. Hazards due to pesticide related problems are increasing at many levels and are very common when attempting to control soil insect pests.

Neither traders nor the users are well aware in the aspect of safe handling of chemical compounds and it is rather haphazard in case of soil pest control. Soil is the major habitat for 
useful as well as harmful organisms. It is not uncommon of using obsolete pesticide in Nepal because the lack of mechanisms of strict regulation on pesticide uses. In some vegetable growing of Nepal, hazards related to pesticide use has becoming serious threat than the pest incurred losses themselves. Some of the issues related to appropriate choices of the pesticide, their formulation, application, and consideration for waiting period are seldom considered. As a means of soil pest control, farmer use some of the dreaded chemicals without considering pest biology, residual effect of pesticides in the soil environment and on the health of the consumers. These factors have led researchers to focus on the development of alternative control measures of pesticides. The best possible alternative would be the use of microbial pest control based on insect killing fungus within the genera of Metarhizium anisopliae and Beauveria bassiana (G. C. et al., 2006). Similarly, other options would be insect parasitic nematodes within the genera of Steinernematids and Heterorhabditis (G. C., 1998). Search on other control agents such as protozoa (Nosema locusta) are underway in some of the developed agriculture. However, in our context, use of further groups of biocontrol agent such insect killing fungus would be possible.

\section{POTENTIAL ALTERNATIVES TO WHITE GRUBS AND OTHER SOIL INSECT CONTROL}

Use of indigenous fungal pathogens in the genera Metarhizium and Beauveria are excellent candidates for the control of white grubs. Beside this insect, they are reported to be useful against red ants (Dorylus orientalis), cut worm (Agrotis segetum) etc. Use of Metarhizium commercially available as "Green Muscle" has long been practiced in Africa against locust and grasshoppers. Microbial control has been a component of integrated pest management (IPM) strategies in developing country for many years, enjoying particular success in Asia and South America, although successful approach for microbial control have evolved worldwide ( $\mathrm{Fx}$, 1949). Similarly, Metarhizium and Beauveria based mycopesticides are successfully used in Switzerland and some other European countries, where health consideration are more rigorous. Suitability of these agents to control white grubs is also reported in India by a number of scientists. An attribute making the fungi as ideal biological insecticide is due to broad host range, high virulence, safety for non-target organisms, compatibility with some pesticides, ease of production with local materials and application without using costly equipments.

M. anisopliae is well known for its ability to control pest insects. It has been developed into commercial products for use in several countries, especially in USA, New Zealand, Brazil, Cuba, and Africa and to some extent in Germany, Switzerland, and Austria. A few examples include Bio-Green and Bio-cane granules for control of soil pests of pasture and sugar cane in Australia, Green Muscle for control of locusts in Africa, Ago Bio-control of various pests of ornamental crops in South America, and Bio-Path for control of cockroaches in the United States. In general, different strains of $M$. anisopliae are species specific. While this limits its use as a general pest control, it makes the fungus safer by limiting its effects on non-target organisms. Moreover, the research history of $M$. anisopliae against soil pests is sparse and successful in developed countries where the health consciousnesses are higher. However, it is entirely a unique approach in Nepal.

\section{WHY FUNGUS BASED MICROBIAL CONTROL IN NEPAL?}

Use of fungal pathogen, Metarhizium anisopliae is an appealing alternative and established practice against white grubs control in some of the developed agriculture including in Switzerland. Significance advances on the production and application of Metarhizium based 
bio-pesticide is done in some European and American countries, where health consideration is more rigorous (Zimmermann, 1993). Progresses are also continued in India and other Asian countries (Despande and Tour, 2003). Commercially product of Metarhizium "Green Muscle" has long been practiced in Africa against locust and grasshoppers (Prior et al., 1992). Control of European cockchafer, Melolontha melolontha is a long established practice in Swiss meadow and farmland. It has been used with good success in grassland and orchards for many years. In the earlier days, swarm of $M$. melolontha was targeted with blastospores which subsequently would carryout the disease to the breeding sites of swarming beetles. This method was extensively tested in the north-eastern Switzerland as pilot trials during 1976 and 1982 with a tractor-pulled mist blower followed by large field trials in 1985 and in 1988 with a helicopter (Keller et al., 2000; 1998). Keller et al. (2003) reported that sufficient control was achieved to avoid the damage by white grubs. Following application the fungus grows and sporulates on the kernels and the larvae gets into contact during their movement.

In Nepal, microbial control is entirely a new approach however, attribute making the fungi as ideal biological insecticide is due to broad host range, high virulence, safety to non-target organisms, compatibility with some pesticides, ease of production with local materials and application without using costly equipments (Cisneros, 1984; Moutia, 1936). The prime objective of microbial control in Nepal would be to reduce the indiscriminate use of chemical pesticides and bring down the pest population in a sustainable means so as to increase the farm income. These biopesticides are the major tools for producing organic produce as the country has been the member of World Trade Organisation (WTO), and it has adopted sanitary measures. Biopesticide can be used for producing valuable commodities like organic tea, honey, coffee, pulses and many other crops. There is ample scope of making foreign income by exporting these materials.

Initiatives towards microbial control in Nepal are almost in embryonic stages. However, the studies carried out for about a decade in IAAS, Rampur in several fields in Nepal has shown great promise (G.C. and Keller, 2003; G. C. et. al., 2006). Studies of the production and utilisation of fungal based microbial agents should be prioritised with the involvement of different organisations in Nepal. Working with biopesticides can be done with joint efforts of likely counterparts from national research institutes such as NARC, IAAS, Nepal Academy of Science and Technology (NAST), etc. and development and extension organizations such as DOA, other governmental and non-governmental organizations, private organization, etc. It is highly important to form a national working group team and develop the infrastructures in the appropriate places. Establishment and strengthening of laboratory facilities are necessary to gear up the work. With a defined set of terms of references (TOR), each stakeholder may contribute in their respective roles and responsibilities. At the same time, it is highly important to support with the human and financial resources.

\section{HOW MICROBIAL CONTROL OF WHITE GRUB WAS INITIATED IN NEPAL?}

The overall modality of the study was with three tiers approach: the search of the insect pathogens in the natural environment in Nepal, laboratory screening, tests and knowledge on their handling and field tests of the fungus to devise the microbial control. This study had two components, the study about the hosts' insect, the white grubs and its fungus, Metarhizium anisopliae. Systematic work such as identification of the soil fungus and noxious species of white grubs with its biology, production and application of $M$. anisopliae for white grubs control are being planned in collaboration with the University of Basel, Switzerland and IAAS, Nepal. Additionally, research and extension counterparts are involved through the network of 
working group concept of the 'bio-control of white grubs' project'. Similarly, some of the related research works, such as the effect of insect pathogens on the non-target beneficial organisms are being addressed by the M. Sc. students of IAAS, Rampur. Besides, M. anisopliae another insect pathogenic fungi able to cause white muscardine diseases in the insect, Beauveria bassiana, is also been maintained at IAAS.

\section{WHAT HAS BEEN ACHIEVED SO FAR?}

Until the mid of 2003 no work had been initiated on insect pathogenic fungi in Nepal. However, biological control research financed by Helvetas-Switzerland and initiated by the IAAS, Rampur in collaboration with Federal Research Station for Agriculture and Agroecolgy (FAL) and University of Basel, Switzerland indicated a high potential for biological control with insect pathogens, Metarhizium anisopliae, in Nepal. The research was prompted by the serendipitous discovery of $M$. anisopliae (in case of Nepal) infected white grubs during the exploratory study at IAAS, Rampur in 2002. The indigenous species of Metarhizium anisopliae was identified by Dr. Siegfied Keller, scientist, FAL, Switzerland and damaging species of white grubs by Prof. Dr. Peter Nagel, Basel University, Switzerland. Efficacy of indigenous pathogens and foundation work were conducted during the exploratory study.

Immediately following the initial discovery of the insect fungus M. anisopliae in Nepal, series of experiments were initiated since the beginning of 2003. Harvesting of the new isolates of insect fungus was conducted from the soil and insects body cadavers. They were isolated, reisolated and maintained in the semi selective medium comprised with peptone, agar-agar, glucose, streptomycin, tetracycline, cyclohexamide and dodine. Regular host passage was performed in the original hosts in order to maintain the virulence of the isolates. Preliminary screening of the fungus isolates was carried out from the time and dose related bioassays. Identification of virulent strains of the fungus followed by mass production into suitable substrate, peeled barley kernels. Field releases were done in three different cropping patterns in lower altitude (Chitwan and Nawalparasi), mid altitudes (Tanahun) and high altitude (Sindhupalchowk). Preliminary results were encouraging towards the goal of the study.

Laboratory facility has been established in IAAS, Rampur at the premises of Entomology Department. In order to produce the fungus in larger scale, it is necessary to up grade or establish the similar facilities in the private organisation. Similarly, present method of production into barley kernels seems somehow tedious and expensive because of the barley substrate. Also, it is bulky in transportation and may require higher doses to a limited area of experimentation. Therefore, the production method may be adopted into different formulation such as dust and liquid. This later method may allow the access for applying the fungus against different target pests such as aerial feeding as well as soil hibernating etc. For this it is important to establish the link with the likely partner organisations that are active in the country and also at the international level.

\section{LESSONS LEARNT FROM SWISS AGRICULTURE RESEARCH}

Swiss Development Co-operation (SDC), HELVETAS, Sustainable Soil Management ProgrammeNepal (SSMP-N) are some of the Swiss Government funding organisations in Nepal. Since its inception, SSMP-N, has demonstrated greater success in improving the production and productivity of the hill farms through the improvement of soil health especially in upland agriculture in Nepal. Within the framework of the soil health improvement programme, it has 
emphasised the eco-friendly control of soil inhabiting pests such as white grubs, red ants, termites, etc. Considering these facts, an exploratory study on microbial control of white grubs was initiated by IAAS, Rampur, Nepal with the encouragement and financial support of SSMP. Technical backstopping for the study has been provided by Agroscope Federal Research Station for Agriculture and Agroecology (FAL), Reckenloz, Zurich, Switzerland. The foundation work so far done in IAAS, Rampur could be inspiring sources for Nepal where further activities can be geared up.

Use of insect pathogenic fungi as a means to control Melolontha melolontha (Coleopter: Scarabaeidae) is a long established practice in Swiss farming. Metarhizium anisopliae and Beauveria bassiana based mycopesticides have been used with good success to control the white grubs prevalent in the meadows. Long term experimentation are been carried out in controlling Melolontha and Hoplia species of white grubs in the grazing and cultivation area in Switzerland. In the long term experimentation plots, the initial dose of the fungus has been significantly reduced, which has saved labour as well as capital resources. Efficacy of mycopesticides and economics of production have been verified over the years in number of developed countries. In addition, the demand for microbial pesticides is globally increasing because of the health consciousness of the bio-product consumers. Therefore, this idea was considered worthy to explore the use of $M$. anisopliae as a potential biological control of white grubs in Nepal.

\section{THE WAY FORWARD FOR MICROBIAL CONTROL OF SOIL PESTS IN NEPAL}

Since the government and donor organisations have been playing a significant role in creating awareness against pesticides, present situation in Nepal is favourable for the initiation of biocontrol programmes against several insect pests in general and soil pests in particular. Similarly, Government of Nepal $(\mathrm{GoN})$, has emphasised the need for integrated pest management (IPM) and the use of natural resources in its long term planning. There is widespread concern about the hazardous effect of chemical pesticides. As a result health consciousness has been increased through the IPM networks of the Department of Agricultural of Nepal. The demand for such types of produce that had been produced in chemical free situation is slowly increasing, especially after the emphasis on eco-tourism in the country. Moreover, consumers' concerns towards the organic products are gradually increasing in the country. Because of this, the potential of organic food shops have been realised and a few are already established in some parts of the country. Some of the products are being exported to foreign countries and there are lot of prospects for making good money.

In another hand, there are no chemical pesticide manufacturing industries in the country and almost all synthetic chemicals are imported from abroad, the majority from India, with some from Japan and Korea. The use of chemical pesticides is very costly and can be difficult to access in some parts of Nepal because of the lack of transportation facilities. Additionally, the purchasing power of the farmer is very low. At the same time, hazards related to misuse of pesticides is likely higher because of the farmer's illiteracy. These issues are all contributing towards the potentiality of microbial control in Nepal and are felt that this type of control should be implemented without delay. In the long run, with trained manpower and suitable infrastructure, fungal based pesticides could be one of the best solutions to control white grubs and other soil pests.

Based on the experience of Swiss Agricultural Research, mycopesticides can be produced using local materials such as low quality rice, barley, etc. and applied with existing farmers' 
practices. In the same way, it can be produced in the form of dust and liquid form suitable to targeting aerial feeding pests besides soil dwelling pests. Application of such biopesticides is compatible with the existing farmer's practices. A better understanding of epizootiology and the environmental constraints are also important and initially could be addressed by the introduction of trained manpower and IPM experts. Farmers can be educated through the network of governmental and non-governmental organisations for the production, application and management of cropping habitats by reducing the use of highly hazardous chemical pesticides. The outcomes so far achieved in this regard will have long lasting effect mainly through the capacity building of the research, extension and teaching organizations of Nepal. These will further contribute in producing quality food through the reduction of the losses due to pest attack in upland crops.

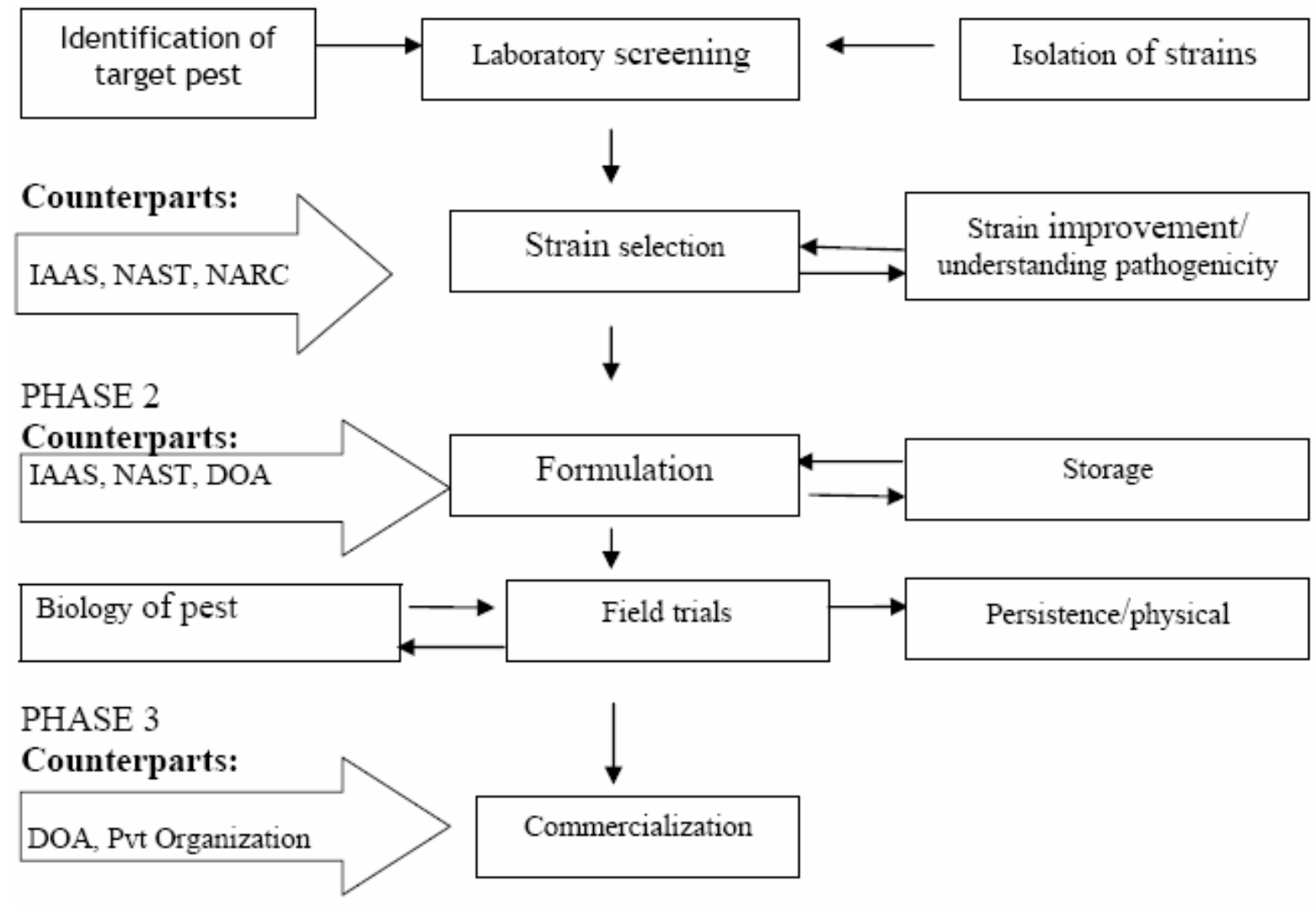

Figure 1: Suggested strategy for the development of fungal based mycoinsecticides in Nepal

\section{FUTURE MODALITY}

Entomogenous fungus have great promise for use as biological control agents against different insects however, their infectivity is quite different depending on fungus species and developmental stage of the insects (Samson, 1981). Therefore, when a particular insect pest control program is considered using these fungi, most suitable species or strains of the fungus have to be taken into account. Similarly, dose and time of exposure of the host to insect fungus and time taken to kill the host are also important parameters for evaluating virulence of insect fungus. Fungi which need shorter exposure period and kill the host quickly are very 
important in the practical application. Until now mass production was followed in autoclavable poly bags which has demonstrated the feasibility but also the importance of the bag quality and assured availability. Good fungus quality was only achieved with such types of bags and used therefore many years (Keller, 2004). Additional efforts must be undertaken to develop a production system which is based only on materials available on the national market. The development of commercial products based on entomopathogenic fungi for the use in integrated pest management program needs several steps. Fungal species and isolates must first be obtained from diseased insects or from the environment, and identified. The most promising candidates are evaluated under controlled condition and produced in large scale as mycopesticides for field tests.

An outline of the major phases of research and major counterparts towards the microbial control of white grubs in Nepal is proposed in flow chart 1.

\section{ACKNOWLEDGMENTS}

We are greatly indebted to Dr. Georg Weber, B. P. Tripathi former directors, SSMP-Nepal, Dr. Matin Dietz, Helvetas, Dr. N. P. Rajbhandari, Team Leader of the "Sustainable Soil Management Programme", Nepal, for their generous encouragement in initiating this kind of work. This work would not have been initiated at this time in Nepal without Helvetas support and initiation. Similarly, we express our sincere appreciation for Helvetas-Switzerland for financial support.

Thanks are also due Prof. Dr. D. D. Dhakal, Prof. Dr. Tej Bahadur K. C. and Prof. Dr. S. M. Shrestha for their kind support during the entire work in IAAS, Rampur. We express our deepest admiration to Mr. Tika Ram Bagale and participant farmers, without their support, this work would not have been successful. The financial assistance of the Swiss Government through Helvetas is gratefully acknowledged.

\section{References}

Dahal, L., 1995. A study on pesticide pollution in Nepal. National Conservation Strategy Implementation Project, Kathmandu.

Deshpande, M. V., 1999. Mycopesticide production by fermentation: Potential and challenges. Crit. Rev. Microbiol. 25:229-243.

Fox, C. J. S., 1949. The incidence of green muscardine in the European wireworm, Agriotes obscurus (Linnaeus), in Nova Scotia. Journal of Insect Pathology 3: 94-95.

GC, Y. D., 1997. Management of Helicoverpa armigera with Entomopathognic Nematodes (Steinernematids and Heterorhabditis). M. Sc. Thesis. Reading University, Berkshire, England, UK, Pp 76.

GC, Y. D., 2006. White grubs (Coleoptera: Scarabaeidae) associated with Nepalese agriculture and their control with indigenous entomopathogenic fungus (Metarhizium anisopliae (Metsch.) Sorokin, PhD Thesis. University of Basel, Switzerland, Pp 250.

GC, Y. D., and Keller and Nagel, P. 2003. Microbial control of white grubs with entomopathogenic fungi: potentials and opportunity in Nepalese agriculture. Proceedings of the fourth national conference on science and technology, March 23-26, 2004, Kathmandu, Nepal, Pp. 96-105.

Keller, S., 2004. Versuche zur Bekämpfung von Maikäfer-Engerlingen durch Bodenbehandlungen mit dem Pilz Beauveria brongniartii (Sacc.) Petch. Laimburg Journal 1: 265-269. 
Keller, S., 1998. Use of fungi for pest control in sustainable agriculture. Phytoprotection 79 (Suppl.): 56-60.

Keller, S., David-Henriet, A.-I. and Schweizer, C. 2000. Insect pathogenic soil fungi from Melolontha melolontha control sites in the canton Thurgau. Bull. IOBC/WPRS 23(8), 73-78.

Keller, S., P. Kessler and C. Schweizer, 2003. Distribution of insect pathogenic soil fungi in Switzerland with special reference to Beauveria brongniartii and Metarhizium

Prior, C., L.J. Lomer, H. Herren, S. Paraiso, C. Kooyman and J.J. Smit, 1992. The IIBC/IITA/DFPV collaborative research programme on biological control of locusts and grasshoppers. p. 8-18. In: Lomer, C. J. and Prior, C. (eds.). Biological control of locusts and grasshoppers. Oxon, UK: CAB International.

Zimmermann, G., 1993. The entomopathogenic fungus Metarhizium anisopliae and its potential as a biocontrol agent. Pestic. Sci. 37: 375-379.

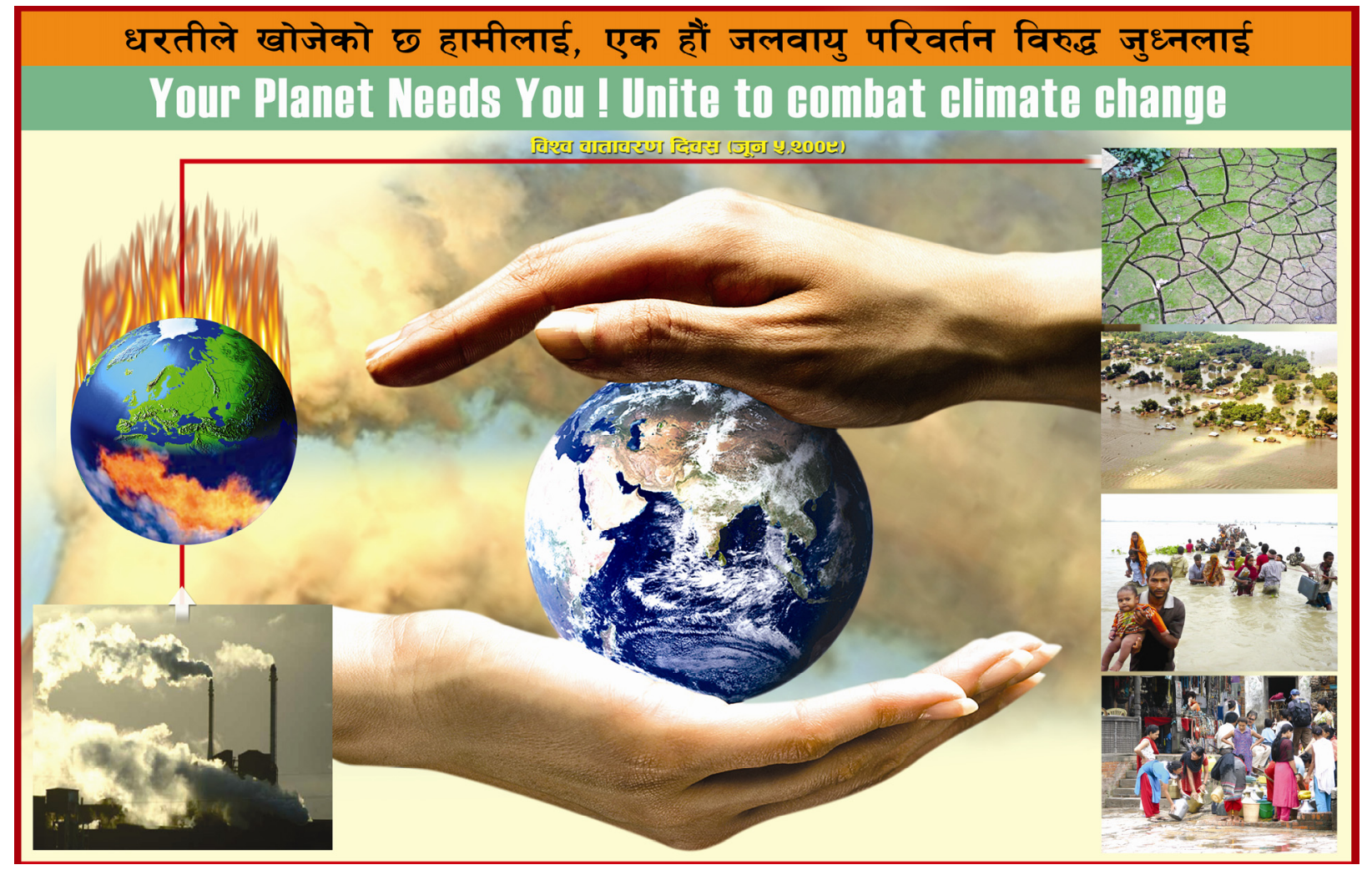

Ministry of Agriculture and Cooperatives

Gender Equity and Environment Division

Agriculture Environment and Biodiversity Section

Singh Durbar, Kathmandu, Nepal.Email: geed.moac@gmail.com 